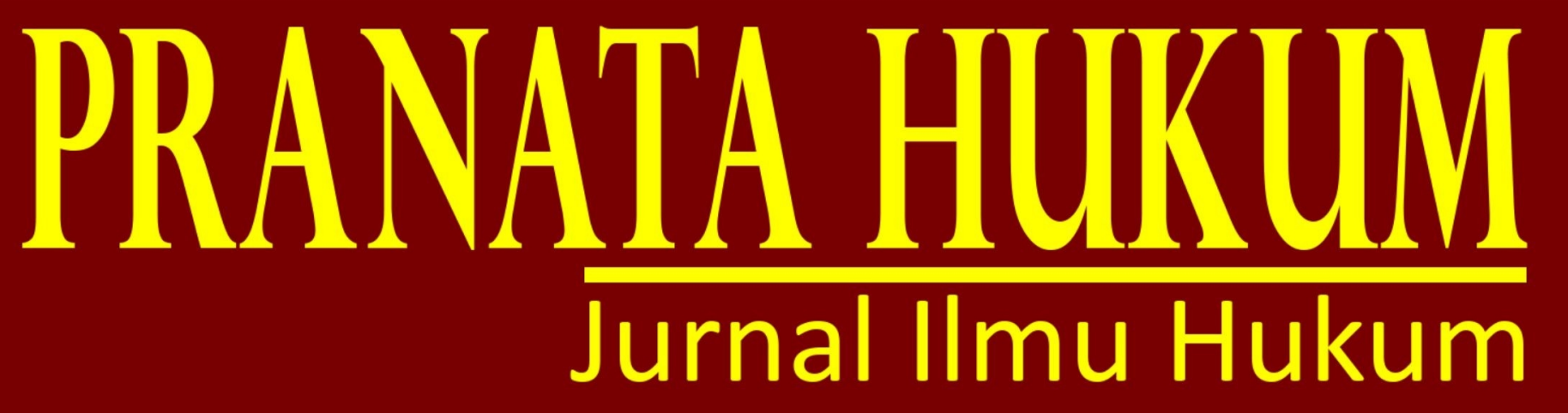

e-ISSN 2685-3213 | p-ISSN 1907-560X

EFEKTIVITAS ASEAN CONVENTION ON COUNTER TERRORISM DI DALAM MEMBERANTAS PEMBAJAKAN DI WILAYAH PERAIRAN ASIA TENGGARA

Rafi Darajati, Muhammad Syafei

PERLINDUNGAN HUKUM PENGGUNA JALAN DARI ANGKUTAN UMUM ONLINE PADA PENGGUNAAN TELEPON SAAT MENGEMUDI KENDARAAN

Rissa Afni Martinouva

ANALISIS PERTANGGUNGJAWABAN PELAKU TINDAK PIDANA MELAKUKAN PENEBANGAN POHON DALAM KAWASAN HUTAN TANPA IJIN YANG BERWENANG

Sukoco SP, Erlina B , Eddy S Wirabhumi

PERLINDUNGAN HUKUM PASIEN PADA BIDAN PRAKTIK MANDIRI DI INDONESIA PASCA DIKELUARKANNYA UNDANG-UNDANG NOMOR 4 TAHUN 2019 TENTANG KEBIDANAN Aditia Arief Firmanto

FUNGSI PENGAWASAN PERADILAN TATA USAHA NEGARA TERHADAP PERBUATAN PEMERINTAH PASCA UNDANG-UNDANG NOMOR 30 TAHUN 2014 TENTANG ADMINISTRASI PEMERINTAHAN Muhammad Rusjana

PELAKSANAAN PENGADAAN BARANG/JASA PEMERINTAH DITINJAU DARI PERPRES NOMOR 16 TAHUN 2018 TENTANG PENGADAAN BARANG/JASA PEMERINTAH DI KANTOR PERTANAHAN KOTA BANDAR LAMPUNG Aryana Wisastra, Baharudin, Indah Satria

KEWAJIBAN TANGGUNG JAWAB SOSIAL PERUSAHAAN (CORPORATE SOCIAL RESPONSIBILITY) DI INDONESIA: ANTARA LEGAL OBLIGATION ATAU MORAL OBLIGATION

Dani Amran Hakim, Dania Hellin Amrina

IMPLEMENTASI PERATURAN MENTERI AGRARIA DAN TATA RUANG/KEPALA BADAN PERTANAHAN NASIONAL NOMOR 13 TAHUN 2017 TENTANG TATA CARA BLOKIR DAN SITA PADA KANTOR PERTANAHAN KOTA BANDAR LAMPUNG

Sholin Erbin M Rajagukguk, Lintje Anna Marpaung, Herlina Ratna Sumbawa Ningrum

PEMBERIAN PATEN OBAT-OBATAN DAN PEMENUHAN HAK ASASI MANUSIA TERHADAP KESEHATAN DI INDONESIA

Chandra Muliawan

\begin{tabular}{c|c|c|c|c|}
\hline $\begin{array}{c}\text { PRANATA } \\
\text { HUKUM }\end{array}$ & $\begin{array}{c}\text { Volume } \\
14\end{array}$ & $\begin{array}{c}\text { Nomor } \\
\mathbf{2}\end{array}$ & $\begin{array}{c}\text { Halaman } \\
96-222\end{array}$ & $\begin{array}{l}\text { Bandar } \\
\text { Lampung } \\
\text { Juli 2019 }\end{array}$ \\
\hline
\end{tabular}




\section{PRANATA HUKUM}

Jurnal Ilmu Hukum

Magister Hukum

Universitas Bandar Lampung

Terbit Pertama Kali, Juli 2006

Terbit Dua Kali Setahun, Setiap Januari dan Juli

PENANGGUNG JAWAB

Rektor Universitas Bandar Lampung

KETUA PENYUNTING

Prof. Dr. Lintje Anna Marpaung, S.H., M.H

WAKIL KETUA PENYUNTING

Dr. Bambang Hartono, S.H., M.Hum

PENYUNTING PELAKSANA

Dr. Tami Rusli, S.H., M.Hum

Dr. Erlina B, S.H., M.H

Dr. Zainab Ompu Jainah, S.H., M.H

Indah Satria, S.H., M.H

Yulia Hesti, S.H., MH

\section{PENYUNTING AHLI (MITRA BESTARI)}

Prof. Dr. I Gusti Ayu Ketut Rachmi Handayani, S.H., M.M (Universitas Sebelas Maret) Prof. Dr. I Gede A.B Wiranata, S.H., M.H (Universitas Lampung) Dr. Nurhadiantomo, S.H., M.Hum (Universitas Muhammdiyah Surakarta) Dr. Erina Pane, S.H., M.H (UIN Lampung)

Alamat:

Kampus B Universitas Bandar Lampung

J1. Z.A Pagar Alam No.89 Labuhan Ratu, Bandar Lampung 35142

Telp: 0721-789825 Fax: 0721-770261

Email: jurnal.mh@ubl.ac.id 


\title{
PELAKSANAAN PENGADAAN BARANG/JASA PEMERINTAH DITINJAU DARI PERPRES NOMOR 16 TAHUN 2018 TENTANG PENGADAAN BARANG/JASA PEMERINTAH DI KANTOR PERTANAHAN KOTA BANDAR LAMPUNG
}

\author{
Aryana Wisastra, ${ }^{1}$ Baharudin, ${ }^{2}$ Indah Satria ${ }^{3}$
}

\begin{abstract}
Indonesia began to regulate the procurement of goods/services electronically from the government since 2010. This is indicated by the appointed Presidential regulation number 54 year 2010 as amended by Presidential Regulation No. 4 year 2015, then amended again to be presidential Regulation No. 16 year 2018 on procurement of goods/services Government. The problem that will be discussed is how the implementation of goods procurement/Government services are reviewed from the Presidential Decree No. 16 of 2018 at the Land Office of Bandar Lampung, what are the inhibitory factors in the implementation of the procurement of goods/services in the Office Land of Bandar Lampung. The research methods used are normative and empirical juridical, using secondary and primary data. Results of the research from the implementation of goods procurement/Government Services reviewed from Presidential Decree No. 16 of 2018 in the Land office of Bandar Lampung now has referred to the Presidential Decree No. 16 of 2018, the inhibitory factor in the implementation of goods /services in the Land office of Bandar Lampung City, among others, lack of human resources that have a certificate of expertise, network/servers that are frequent disruptions and difficult when creating the approximate price yourself.
\end{abstract}

\section{Keywords: procurement, goods/services, land}

\section{PENDAHULUAN}

Pemerintah sebagai organisatoris negara berkewajiban memenuhi kebutuhan masyarakat dan kegiatan penyelenggaraan pemerintahan. Salah satu kebutuhan masyarakat dan penyelenggaraan pemerintahan yang cukup penting adalah pengadaan barang/jasa. Penyelenggaraan pemerintahan Republik Indonesia pada dasawarsa terakhir telah memasuki era reformasi birokrasi, dimana pemerintah wajib menerapkan prinsip-prinsip dasar tata kelola yahoo.co.id

1 Mahasiswa Magister Hukum Universitas Bandar Lampung, aryanawisastra@

2 Dosen Magister Hukum Universitas Bandar Lampung, baharudin@ubl.ac.id

3 Dosen Fakultas Hukum Universitas Bandar Lampung, indah.satria@ubl.ac.id 
pemerintahan yang baik (good governance), antara lain transparansi, partisipasi, akuntabilitas dan bebas dari korupsi, kolusi dan nepotisme.

Pengadaan barang/jasa yang sebagian atau seluruhnya dibiayai dari APBN/APBD pelaksanaannya mengacu pada Peraturan Presiden RI (selanjutunya disingkat Perpres) Nomor 54 Tahun 2010 tentang Pengadaan Barang/Jasa Pemerintah yang kemudian digantikan dengan Peraturan Presiden Nomor 16 Tahun 2018 tentang Pengadaan Barang/Jasa pemerintah. Tujuan diberlakukannya Peraturan Presiden ini adalah agar pelaksanaan pengadaan barang/jasa dilakukan secara efisien, efektif, transparan, terbuka, bersaing, adil/tidak diskriminatif, dan akuntabel.

Pada mulanya pelaksanaan pengadaan barang/jasa dilaksanakan secara konvensional yaitu dilaksanakan secara langsung oleh pengguna barang/jasa atau panitia (Purwosusilo, 2014: 33). Namun dalam praktek pelaksanaannya banyak terjadi penyimpangan- penyimpangan dan prinsip-prinsip dan ketentuan pengadaan barang/jasa pemerintah yang diatur dalam kepres 80 tahun 2003 . Penyimpangan tersebut ada yang berwujud penyimpangan administrasi juga berupa tindakan korupsi yang merugikan keuangan negara (Agung Djojosoekarto (ed), 2008, 44). Pada lelang konvensional, aanwijzing dilaksanakan secara terbuka untuk suatu tender. Sehingga mengingat penyedia barang/jasa telah pernah bertemu atau setidak-tidaknya mengetahui siapa saja yang ingin memberikan penawaran dalam lelang, maka penyedia tersebut bisa saja berkomunikasi di lain waktu dan tempat untuk merancang arisan tender. Arisan tender adalah persengkokolan di antara para pelaku usaha untuk menciptakan persaingan semu di antara peserta tender (Adrian Sutedi, 2009, 120). Berdasarkan uraian di atas, yang menjadi permasalahan dalam penelitian ini yaitu bagaimana pelaksanaan pengadaan barang/jasa pemerintah ditinjau dari Perpres Nomor 16 Tahun 2018 di Kantor Pertanahan Kota Bandar Lampung? Apa faktorfaktor penghambat dalam pelaksanaan pengadaan barang/jasa di Kantor Pertanahan Kota Bandar Lampung?. Metodologi Penelitian yang digunakan untuk memecahkan masalah guna memberikan petunjuk tentang yang akan dibahas dan dipertanggungjawabkan kebenarannya, maka dalam penelitian ini diperlukan metode tertentu. Adapun metode penelitian yang peneliti pergunakan dalam kerangka penulisan ini yaitu yuridis normatif dan empiris, menggunakan data sekunder dan primer. 


\section{A. II. PEMBAHASAN}

a. Pelaksanaan pengadaan barang/jasa pemerintah ditinjau dari Perpres Nomor 16 Tahun 2018 di Kantor Pertanahan Kota Bandar Lampung

Menurut Ahmad Aminullah, selaku Kuasa Pengguna Anggaran (KPA) Kantor Pertanahan Kota Bandar lampung Pelaksanaan Pengadaan Barang/Jasa Pemerintah yang dilaksanakan oleh Kantor Pertanahan Kota Bandar Lampung memiliki beberapa tahap yaitu :

1) Pengumuman

2) Pendaftaran dan pengambilan dokumen pengadaan

3) Pemberian penjelasan

4) Pemasukan dokumen penawaran

5) Pembukaan dokumen penawaran

6) Evaluasi penawaran

7) Evaluasi kualifikasi

8) Pembuktian kualifikasi

9) Pembuatan beritaa cara hasil pelelangan

10) Penetapan pemenang

11) Pengumuman pemenang

12) Sanggahan

13) Sanggahan banding (apabila diperlukan), dan

14) Penunjukkan penyedia barang/jasa.

Setelah semua tahapan tersebut dilaksanakan oleh pantia, maka kegiatan selanjutnya adalah:

a) Pembuatan SBPPK oleh Pejabat Pembuat Komitmen

b)Penandatanganan kontrak

c) Pembayaran uang muka

d)Pelaksanaan pekerjaan di lapangan

e) Serah terima pekerjaan

Selain tahapan di atas kita pun tetap mengacu terhadap Perpres Nomor 16 Tahun 2018 tentang pengadaan Barang/Jasa pemerintah. Menurut Wila Arintia. R selaku Pejabat Pembuat Komitmen (PPK) Pertanahan Kota Bandar Lampung, mengatakan bahwa dalam pengadaan barang/jasa pemerintah yang dilaksanakan oleh Kantor Pertanahan Kota Bandar lampung telah mengacu pada Perpres Nomor 16 Tahun 2018 tentang Pengadaan Barang/Jasa.

Menurut Mutiara Safitri selaku Bendahara di Kantor Pertanahan Kota Bandar Lampung, beliau mengatakan bahwa pelaksaaan pengadaaan barang/jasa pemerintah sudah mengacu pada Perpres Nomor 16 Tahun 2018. Pengadaan barang/jasa di Kantor Pertanahan Kota Bandar Lampung telah sesuai dengan 
Perpres Nomor 16 Tahun 2018. Seperti pada tahun 2018 Kantor Pertanahan Kota Bandar Lampung melakukan Pengadaan Langsung Pekerjaan Konstruksi/Jasa berupa perbaikan loket yang bernilai Rp.150.000.000, jumlah ini masih di bawah Rp.200.000.000 yang merupakan batas maksimal untuk melakukan pangadaan barang/jasa secara langsung.

Menurut Sholin selaku Pejabat Pengadaaan di Kantor Pertanahan Kota Bandar lampung, beliau mengatakan bahwa pengadaan barang/jasa pemerintah masih masa transisi dari yang tadinya menggunakan Perpres Nomor 54 Tahun 2010 tentang Pengadaan Barang/Jasa berubah sekarang ke Perpres Nomor 16 tahun 2018 tentang Barang/Jasa. Menurut Candra Cahyadi salah satu anggota Unit Pelayanan Pengadaan (ULP) Kantor Wilayah Provinsi Lampung, belum seluruh satuan kerja dapat melaksanakan pengadaan barang/jasa pemerintah sesuai dengan Perpres Nomor 16 Tahun 2018, beliau mengatakan bahkan yang sesuai dengan Perpres 54 Tahun 2010 belum bisa terlaksana dengan sempurna sampai sekarang ini.

Governance merupakan serangkaian proses interaksi sosial politik antara pemerintah dengan masyarakat dalam berbagai bidang yang berkaitan dengan kepentingan masyarakat dan intervensi pemerintah atas kepentingan-kepentingan tersebut. (Sumarto Hetifa Sj, 2003:89)

Governance merupakan mekanisme-mekanisme, proses-proses dan institusi-institusi melalui warga Negara mengartikulasi kepentingan-kepentingan mereka, memediasi perbedaan-perbedaan mereka serta menggunakan hak dan kewajiban legal mereka. Governance merupakan proses lembaga-lembaga pelayanan, mengelola sumber daya publik dan menjamin realita hak azasi manusia. Dalam konteks ini good governance memiliki hakikat yang sesuai yaitu bebas dari penyalahgunaan wewenang dan korupsi serta dengan pengakuan hak yang berlandaskan pada pemerintahan hukum. (Dede Rosyada, 2000: 56).

Dapat dianalisis bahwa pelaksaan pengadaan barang/jasa pemerintah di Kantor Pertanahan Kota Bandar lampung sudah mengacu pada Perpres Nomor 16 Tahun 2018 tentang Pengadaan Barang/Jasa, dikaitan dengan teori Good Governance menurut Kooiman, governance merupakan serangkaian proses interaksi sosial politik antara pemerintah dengan masyarakat dalam berbagai bidang yang berkaitan dengan kepentingan masyarakat dan intervensi pemerintah atas kepentingan-kepentingan tersebut, maka Perpers Nomor 16 Tahun 2018 tentang Pengadaan Barang/jasa adalah satu wujud untuk menciptakan Good Governance.

Peraturan Presiden Nomor 16 Tahun 2018 dapat dianalisis dari Lembaga Administrasi Negara (LAN) yang menyimpulkan ada sembilan aspek fundamental dalam perwujudan good governance, yaitu: 


\section{Partisipasi (Participation)}

Dilihat dari aspek partisipasi, pelaksanaan Perpres Nomor 16 Tahun 2018 tentang Pengadaan Barang/Jasa pemerintah di Kantor Pertanahan Kota Bandar lampung sudah terpenuhi, terlihat pada proses pelaksaanaan banyak pihak yang ikut berpartisipasi di dalamnya Menurut Ahmad Aminullah, selaku Kuasa Pengguna Anggaran (KPA) Kantor Pertanahan Kota Bandar lampung seperti Kuasa Pengguna Anggaran (KPA), Pejabat Pembuat Komitmen (PPK), Bendahara, Pejabat Pengadaan dan Unit pelayanan Pengadaan (ULP).

2. Penegakan hukum (Rule of Low)

Dilihat dari aspek penegakan hukum, dalam pelaksanaan Perpres Nomor 16 Tahun 2018 tentang Pengadaaan Barang/Jasa Pemerintah terdapat sanksi administrasi maupun sanksi pidana walaupun dari narasumber yang Penulis wawancarai tidak menjelaskannya namun dalam Perpres Nomor 16 Tahun 2018 tentang Pengadaaan Barang/Jasa Pemerintah dijelaskan tentang sanksi yaitu pada BAB XII Bagian Ketiga, Pasal 78 sampai Pasal 82, maka dari aspek penegakan hukum Perpres Nomor 16 Tahun 2018 tentang Pengadaaan Barang/Jasa Pemerintah telah terpenuhi.

\section{Transparansi (Transparency)}

Dilihat dari aspek Transparansi, dalam pelaksanaan Perpres Nomor 16 Tahun 2018 tentang Pengadaaan Barang/Jasa Pemerintah telah memenuhi aspek ini, karena menurut narasumber Ahmad Aminullah selaku Kuasa Pengguna Anggaran (KPA) Kantor Pertanahan Kota Bandar lampung, Wila Arintia. R selaku Pejabat Pembuat Komitmen (PPK) Pertanahan Kota Bandar Lampung dan Mutiara Safitri selaku Bendahara Kantor Pertanahan Kota Bandar lampung mengatakan bahwa saat ini pelaksanaan pengadaan barang/jasa di Kantor Pertanahan Kota Bandar lampung telah mengacu pada Perpres Nomor 16 tahun 2018, maka e-Procurement (pembelian secara elektronik) merupakan salah satu bagian daripada Perpres Nomor 16 Tahun 2018. Perpres ini telah menerapkan sistem elektronik, sehingga transparansi harga barang/jasa dalam pengadaan bisa lebih mudah dalam pengecekan.

\section{Responsif (Responsiveness)}

Pada pelaksanaan Perpres Nomor 16 Tahun 2018 tentang Pengadaaan Barang/Jasa Pemerintah, aspek responsif sudah ada di dalamnya, karena menurut narasumber Ahmad Aminullah selaku Kuasa Pengguna Anggaran (KPA) Kantor Pertanahan Kota Bandar lampung, Wila Arintia. R selaku Pejabat Pembuat Komitmen (PPK) Pertanahan Kota Bandar Lampung dan Mutiara Safitri selaku Bendahara Kantor Pertanahan Kota Bandar lampung mengatakan bahwa saat ini pelaksanaan pengadaan barang/jasa di Kantor Pertanahan Kota Bandar lampung telah mengacu pada Perpres Nomor 16 tahun 2018 walau tidak dijabarkan oleh narasumber secara langsung namun pada BAB XII Pengawasan, Pengaduan, Sanksi 
dan Pelayanan Umum, ini merupakan unsur positif yang ada di Perpres Nomor 16 Tahun 2018 tentang Pengadaaan Barang/Jasa Pemerintah, adanya pengawasan internal dan juga masyarakat bisa mengadu apabila ada kecurangan dalam pengadaan barang/jasa pemerintah.

\section{Konsensus (Consensus Orientation)}

Aspek Konsensus dalam pelaksaanaan Perpres Nomor 16 Tahun 2018 tentang Pengadaaan Barang/Jasa Pemerintah jelas sudah ada di dalamnya, karena menurut narasumber Ahmad Aminullah selaku Kuasa Pengguna Anggaran (KPA) Kantor Pertanahan Kota Bandar lampung, Wila Arintia. R selaku Pejabat Pembuat Komitmen (PPK) Pertanahan Kota Bandar Lampung dan Mutiara Safitri selaku Bendahara Kantor Pertanahan Kota Bandar lampung mengatakan bahwa saat ini pelaksanaan pengadaan barang/jasa di Kantor Pertanahan Kota Bandar lampung telah mengacu pada Perpres Nomor 16 Tahun 2018 walau tidak dijabarkan secara langsung oleh para narasumber, namun terlihat dalam pengadaan barang/jasa pastinya telah dimufakatkan bersama dalam pelaksaanaannya, ada tahapantahapan yang harus dilalui dalam pengadaan barang/jasa pemerintah.

6. Kesetaraan dan keadilan (Equity)

Aspek Kesetaraan dalam pelaksanaan Perpres Nomor 16 Tahun 2018 tentang Pengadaaan Barang/Jasa Pemerintah telah terpenuhi, karena menurut narasumber Ahmad Aminullah selaku Kuasa Pengguna Anggaran (KPA) Kantor Pertanahan Kota Bandar lampung, Wila Arintia. R selaku Pejabat Pembuat Komitmen (PPK) Pertanahan Kota Bandar Lampung dan Mutiara Safitri selaku Bendahara Kantor Pertanahan Kota Bandar lampung mengatakan bahwa saat ini pelaksanaan pengadaan barang/jasa di Kantor Pertanahan Kota Bandar lampung telah mengacu pada Perpres Nomor 16 tahun 2018 walaupun narasumber tidak menjelaskan secara jelas namun salah satu contoh dalam mengadakan lelang tender, semua kontraktor atau penyedia barang bisa ikut asalkan telah memenuhi syarat (tidak bermasalah hukum, dll) dalam mengikuti lelangnya.

7. Efektifitas dan efisien

Aspek efektifitas dan efisien dalam pelaksanaan Perpres Nomor 16 Tahun 2018 tentang Pengadaaan Barang/Jasa Pemerintah telah terpenuhi, karena menurut narasumber Ahmad Aminullah selaku Kuasa Pengguna Anggaran (KPA) Kantor Pertanahan Kota Bandar lampung, Wila Arintia. R selaku Pejabat Pembuat Komitmen (PPK) Pertanahan Kota Bandar Lampung dan Mutiara Safitri selaku Bendahara Kantor Pertanahan Kota Bandar lampung mengatakan bahwa saat ini pelaksanaan pengadaan barang/jasa di Kantor Pertanahan Kota Bandar lampung telah mengacu pada Perpres Nomor 16 tahun 2018 walau tidak dijelaskan secara jelas namun Perpres Nomor 16 tahun 2018 sudah mengenal e-Procurement maka lebih efektif dalam melakukan pengadaan barang/jasa, lebih cepat dan lebih 
mudah. $e$-Procurement merupakan salah satu contoh efektifitas dan efisien dalam pelaksanaan pengadaan barang/jasa pemerintah.

8. Akuntabilitas

Aspek Akuntabilitas dalam pelaksaanaan Perpres Nomor 16 Tahun 2018 tentang Pengadaaan Barang/Jasa Pemerintah juga jelas sudah ada, karena menurut narasumber Ahmad Aminullah selaku Kuasa Pengguna Anggaran (KPA) Kantor Pertanahan Kota Bandar lampung, Wila Arintia. R selaku Pejabat Pembuat Komitmen (PPK) Pertanahan Kota Bandar Lampung dan Mutiara Safitri selaku Bendahara Kantor Pertanahan Kota Bandar lampung mengatakan bahwa saat ini pelaksanaan pengadaan barang/jasa di Kantor Pertanahan Kota Bandar lampung telah mengacu pada Perpres Nomor 16 tahun 2018 walau tidak dijelaskan secara jelas namun dalam Perpres Nomor 16 tahun 2018 pejabat yang berwenang mempunyai tanggungjawab apabila terjadi kesalahan ataupun masalah dalam pengadaan barang/jasa pemerintah, khususnya dalam hal ini pejabat yang berwenang dalam pengadaan barang/jasa di Kantor Pertanahan Kota Bandar lampung

\section{Visi Strategi (Strategic Vision)}

Aspek Visi Stategi dalam pelaksanaan Perpres Nomor 16 Tahun 2018 tentang Pengadaaan Barang/Jasa Pemerintah jelas ada, pemerintah selalu ingin mewujudkan Good Governance maka dari itu Perpres ini adalah perubahan kesekian kalinya dalam pengadaan barang/jasa pemerintah. Menurut narasumber Ahmad Aminullah selaku Kuasa Pengguna Anggaran (KPA) Kantor Pertanahan Kota Bandar lampung, Wila Arintia. R selaku Pejabat Pembuat Komitmen (PPK) Pertanahan Kota Bandar Lampung dan Mutiara Safitri selaku Bendahara Kantor Pertanahan Kota Bandar lampung mengatakan bahwa saat ini pelaksanaan pengadaan barang/jasa di Kantor Pertanahan Kota Bandar lampung telah mengacu pada Perpres Nomor 16 tahun 2018 walau tidak dijelaskan secara jelas namun Perpres Nomor 16 tahun 2018 Strategi yang paling utama di Perpres ini adalah pengadaan barang/jasa secara online, salah satu strategi pemerintah menekan korupsi yang banyak terjadi di lembaga khususnya dalam pengadaan barang/jasa.

\section{b. Faktor-faktor penghambat dalam pelaksanaan pengadaan barang/jasa di Kantor Pertanahan Kota Bandar Lampung}

Menurut Ahmad Aminullah, selaku Kuasa Pengguna Anggaran (KPA) Kantor Pertanahan Kota Bandar lampung faktor penghambat dalam pelaksanaan pengadaan barang/jasa di Kantor Pertanahan Kota Bandar lampung yaitu Sumber Daya Manusia (SDM) yang masih minim keahlian dalam pengadaaan barang/jasa, kemudian masalah Jaringan/server yang sering terjadi gangguan dan masalah pembuatan HPS (Harga Perkiraan Sendiri) yang terlalu lama. 
Menurut Wila Arintia. $\mathrm{R}$ selaku Pejabat Pembuat Komitmen (PPK) Pertanahan Kota Bandar Lampung, faktor penghambat dalam pelaksanaan pengadaan barang/jasa di Kantor Pertanahan Kota Bandar lampung, yaitu pertama, kurangnya Sumber Daya Manusia (SDM) /Pegawai pemerintah yang memiliki sertifikat keahlian pengadaan barang/jasa, sehingga satu kantor Pertanahan hanya memiliki beberapa pejabat pengadaan (untuk pengadaan langsung). Kedua, Jaringan/server LPSE yang telah ditunjuk sebagai tempat/wadah penyampaian lelang terkadang mengalami gangguan. Ketiga, terkadang jangka waktu antara pembuatan HPS (spesifikasi dan harga barang) terlalu lama dengan pembukaan penawaran pemenang lelang, sehingga harga sudah tidak lagi sesuai atau spesifikasi barang tidak ada lagi di pasaran, maka dari itu biasanya diadakan peninjauan dan adendom (untuk pelelangan sederhana).

Menurut Mutiara Safitri selaku Bendahara di Kantor Pertanahan Kota Bandar Lampung, beliau mengatakan bahwa faktor-faktor penghambat dalam pelaksanaan pengadaan barang/jasa di Kantor Pertanahan Kota Bandar Lampung yaitu:

a) Terbatasnya tenaga/SDM yang memiliki sertifikat pengadaan barang/jasa.

b)Kurangnya keahlian memakai program dalam e-Procurement atau memakai internet.

c) Belum adanya integrasi system dalam $e$-Procurement antar pihak-pihak terkait/instansi terkait untuk klarifikasi dokumen.

d)Kesulitan dalam melihat kelegalan suatu dokumen yang tercantum dalam $e$ - Procurement, seperti materai dan tanda tangan.

Menurut Sholin selaku Pejabat Pengadaaan di Kantor Pertanahan Kota Bandar lampung, beliau mengatakan bahwa faktor penghambat pengadaan barang/jasa pemerintah yaitu kurangnya Sumber Daya Manusia (SDM) yang ahli di Kantor Pertanahan Kota Bandar lampung. Menurut Candra Cahyadi salah satu anggota Unit Pelayanan Pengadaan (ULP) Kantor Wilayah Provinsi Lampung, faktor penghambat dalam pelaksanaan pengadaan barang/jasa di Kantor Pertanahan Kota Bandar lampung, yaitu ada faktor internal dan faktor eksternal. Faktor internal yaitu Pertama, belum adanya suatu unit/bidang/jabatan fungsional khususyg menangani pelaksanaan PBJ di masing-masing satuan kerja, hanya beberapa satuan kerja yang sudah memilikinya. Hal ini menyebabkan kurangnya rasa tanggungjawab bagi pelaksana PBJ. Selain itu sebagai ASN tentu akan lebih memilih Tusi yang melekat padanya daripada mengerjakan tugas yang lebih berat resikonya. Kedua, kurangnya kemampuan individu yang telah memegang Sertifikat Keahlian PBJ bila di praktekkan langsung dalam Pelaksanaan PBJ. Ketiga, Kurangnya perlindungan dari instansi bila pelaksana PBJ terbentur suatu masalah dalam melaksanakan PBJ. Keempat, belum adanya jaminan bahwa memiliki sertifikat keahlian PBJ yang notabene lulus ujian PBJ dapat melaksanakan 
PBJ. Faktor eksternal yaitu peraturan mengenai PBJ masih sulit dipahami, kurangnya pelatihan dan bimbingan dari instansi tentang PBJ, sosialisasi perkembangan peraturan PBJ masih kurang, dan banyaknya tekanan pada pelaksana PBJ.

Lawrence M. Friedman mengemukakan bahwa efektif dan berhasil tidaknya penegakan hukum tergantung tiga unsur sistem hukum, yakni struktur hukum (struktur of law), substansi hukum (substance of the law) dan budaya hukum (legal culture). Struktur hukum menyangkut aparat penegak hukum, substansi hukum meliputi perangkat perundang- undangan dan budaya hukum merupakan hukum yang hidup (living law) yang dianut dalam suatu masyarakat.

Dapat dianalisis bahwa faktor penghambat pengadaan barang/jasa di Kantor Pertanahan Kota Bandar lampung teridiri dari faktor internal dan faktor eksternal.

Faktor internal yaitu pertama, kurangnya Sumber Daya Manusia (SDM) /Pegawai pemerintah yang memiliki sertifikat keahlian pengadaan barang/jasa, sehingga satu kantor Pertanahan hanya memiliki beberapa pejabat pengadaan (untuk pengadaan langsung). Kedua, Jaringan/server LPSE yang telah ditunjuk sebagai tempat/wadah penyampaian lelang terkadang mengalami gangguan. Ketiga, terkadang jangka waktu antara pembuatan HPS (Harga Perkiraan Sendiri) terlalu lama dengan pembukaan penawaran pemenang lelang, sehingga harga sudah tidak lagi sesuai atau spesifikasi barang tidak ada lagi di pasaran, maka dari itu biasanya diadakan peninjauan dan adendom (untuk pelelangan sederhana).

Faktor eksternal yaitu pertama, aturan yang ada masih sulit dipahami. Kedua, kurangnya sosialisasi dari pemerintah tentang perkembangan aturan pengadaan barang/jasa. Ketiga banyak tekanan dari luar. Berdasarkan Teorinya Lawrence M. Friedman mengemukakan bahwa efektif dan berhasil tidaknya penegakan hukum tergantung tiga unsur sistem hukum, yakni:

1) Struktur Hukum (struktur of law)

Dalam teori Lawrence Meir Friedman hal ini disebut sebagai sistem Struktural yang menentukan bisa atau tidaknya hukum itu dilaksanakan dengan baik. Menurut Ahmad Aminullah, selaku Kuasa Pengguna Anggaran (KPA) Kantor Pertanahan Kota Banda Lampung, Wila Arintia. R selaku Pejabat Pembuat Komitmen (PPK) Pertanahan Kota Bandar Lampung, Sholin selaku Pejabat Pengadaaan di Kantor Pertanahan Kota Bandar lampung dan Candra Cahyadi salah satu anggota Unit Pelayanan Pengadaan (ULP) Kantor Wilayah Provinsi Lampung pelaksaan pengadaan barang/jasa pemerintah selama ini sudah mengacu pada Perpres Nomor 16 Tahun 2018 tentang Pengadaan Barang/Jasa Pemerintah artinya lembaga (Kantor Pertanahan Kota Bandar lampung) telah bisa melaksanakan Perpres tersebut, namun dalam pelaksaannya terdapat beberapa 
hambatan yang terjadi seperti menurut Mutiara Safitri selaku Bendahara di Kantor Pertanahan Kota Bandar Lampung yaitu:

a. Terbatasnya tenaga/SDM yang memiliki sertifikat pengadaan barang/jasa.

b. Kurangnya keahlian memakai program dalam e-Procurement atau memakai internet.

c. Belum adanya integrasi system dalam $e$-Procurement antar pihak-pihak terkait/instansi terkait untuk klarifikasi dokumen.

d. Kesulitan dalam melihat kelegalan suatu dokumen yang tercantum dalam $e$ - Procurement, seperti materai dan tanda tangan.

2) Substansi Hukum (substance of the law)

Dalam teori Lawrence Meir Friedman hal ini disebut sebagai sistem substansial yang menentukan bisa atau tidaknya hukum itu dilaksanakan. Substansi juga berarti produk yang dihasilkan oleh orang yang berada dalam sistem hukum yang mencakup keputusan yang mereka keluarkan, aturan baru yang mereka susun. Dalam pelaksanaan pengadaan barang/jasa Menurut narasumber Ahmad Aminullah selaku Kuasa Pengguna Anggaran (KPA) Kantor Pertanahan Kota Bandar lampung, Wila Arintia. R selaku Pejabat Pembuat Komitmen (PPK) Pertanahan Kota Bandar Lampung dan Mutiara Safitri selaku Bendahara Kantor Pertanahan Kota Bandar lampung mengatakan bahwa saat ini pelaksanaan pengadaan barang/jasa di Kantor Pertanahan Kota Bandar lampung telah mengacu pada Perpres Nomor 16 tahun 2018 walau tidak dijelaskan secara jelas namun Perpres Nomor 16 tahun 2018 pelaksaaan sudah jelas tahapannya, siapa pelaku, apa kewenangannya, tata cara, serta sanksi telah diatur sehingga pelaksanaan pengadaan barang/jasa hanya tinggal mengikuti Perpres Nomor 16 tahun 2018 tentang Pengadaan Barang/Jasa Pemerintah.

3) Budaya Hukum (legal culture)

Budaya Hukum menurut Lawrence Meir Friedman adalah sikap manusia terhadap hukum dan sistem hukum-kepercayaan, nilai, pemikiran, serta harapannya. Kultur hukum adalah suasana pemikiran sosial dan kekuatan sosial yang menentukan bagaimana hukum digunakan, dihindari, atau disalahgunakan. Budaya hukum erat kaitannya dengan kesadaran hukum masyarakat. Semakin tinggi kesadaran hukum masyarakat maka akan tercipta budaya hukum yang baik dan dapat merubah pola pikir masyarakat mengenai hukum selama ini. Menurut narasumber Ahmad Aminullah selaku Kuasa Pengguna Anggaran (KPA) Kantor Pertanahan Kota Bandar lampung, Wila Arintia. R selaku Pejabat Pembuat Komitmen (PPK) Pertanahan Kota Bandar Lampung dan Mutiara Safitri selaku Bendahara Kantor Pertanahan Kota Bandar lampung mengatakan bahwa saat ini 
pelaksanaan pengadaan barang/jasa di Kantor Pertanahan Kota Bandar lampung telah mengacu pada Perpres Nomor 16 tahun 2018 walau tidak dijelaskan secara jelas namun dalam Perpres Nomor 16 tahun 2018 terdapat beberapa perubahan pola pelaksaaan pengadaan barang/jasa dari perpres sebelumnya, seperti penggunaan e-Procurement ini merupakan salah satu cara agar terciptanya transparansi serta meminimalisir terjadinya Korupsi Kolusi Nepotisme (KKN) dalam pengadaan barang/jasa pemerintah, walaupun dalam pelaksaannya menurut narasumber masih terhambat oleh jaringan/server yang sering gangguan.

\section{PENUTUP}

Pelaksanaan pengadaan barang/jasa pemerintah di Kantor Pertanahan Kota Bandar lampung sudah mengacu pada Perpres Nomor 16 Tahun 2018 tentang Pengadaan Barang/Jasa, dikaitan dengan teori Good Governance menurut Kooiman, governance merupakan serangkaian proses interaksi sosial politik antara pemerintah dengan masyarakat dalam berbagai bidang yang berkaitan dengan kepentingan masyarakat dan intervensi pemerintah atas kepentingankepentingan tersebut, maka Perpers Nomor 16 Tahun 2018 tentang Pengadaan Barang/jasa adalah satu wujud untuk menciptakan Good Governance. Faktor penghambat pengadaan barang/jasa di Kantor Pertanahan Kota Bandar lampung teridiri dari faktor internal dan faktor eksternal. Faktor internal yaitu pertama, kurangnya Sumber Daya Manusia (SDM) /Pegawai pemerintah yang memiliki sertifikat keahlian pengadaan barang/jasa, sehingga satu kantor Pertanahan hanya memiliki beberapa pejabat pengadaan (untuk pengadaan langsung). Kedua, Jaringan/server LPSE yang telah ditunjuk sebagai tempat/wadah penyampaian lelang terkadang mengalami gangguan. Ketiga, terkadang jangka waktu antara pembuatan HPS (spesifikasi dan harga barang) terlalu lama dengan pembukaan penawaran pemenang lelang, sehingga harga sudah tidak lagi sesuai atau spesifikasi barang tidak ada lagi di pasaran, maka dari itu biasanya diadakan peninjauan dan adendom (untuk pelelangan sederhana). Faktor eksternal yaitu pertama, aturan yang ada masih sulit dipahami. Kedua, kurangnya sosialisasi dari pemerintah tentang perkembangan aturan pengadaan barang/jasa. Ketiga banyak tekanan dari luar.

Diharapkan kepada pemerintah dapat mencari solusi terhadap faktorfaktor penghambat dalam pelaksanaan pengadaan barang/jasa yang mengacu pada Perpres Nomor 16 Tahun 2018 khususnya di Kantor Pertanahan Kota Bandar lampung, sehingga bisa membuat pelaksanaan pengadaan barang/jasa menjadi lebih maksimal hasilnya. Penerapan Perpres Nomor 16 Tahun 2018 tentang Pengadaan Barang/Jasa Pemerintah belum bisa dilaksanakan sepenuhnya karena masih masa trasnsisi dari Perpres Nomor 54 Tahun 2010 tentang Pengadaan Barang/Jasa Pemerintah ada baiknya para pajabat maupun satuan 
kerja pengadaan barang/jasa pemerintah khusunya di Kantor Pertanahan Kota Bandar Lampung cepat sepenuhnya mengacu pada Perpres Nomor 16 Tahun 2018, agar dapat tercipta kemajuan daripada aturan yang baru tersebut.

\section{DAFTAR PUSTAKA}

\section{A. Buku}

Agung Djojosoekarto (ed). 2008. E-Procurement di Indonesia, Pengembangan Layanan Pengadaan Barang dan jasa Secara Elektronik. Kemitraan Partnership dan LPSE Nasional. Jakarta.

Adrian Sutedi. 2009. Apek Hukum Pengadaan Barang dan Jasa dan Berbagai Permasalahannya. Sinar Grafika. Jakarta.

Dede Rosyada Dkk. 2000. Demokrasi, Hak Asasi Manusia Dan Masyarakat Madani. ICCE UIN Syarif Hidayatullah. Jakarta

Purwosusilo, 2014, Aspek Hukum Pengadaan Barang dan Jasa, Perpustakaan Nasional, Jakarta.

Sumarto Hetifa Sj. 2003. Inovasi. Partisipasi dan Good Governance. Yayasan Obor Indonesia. Bandung.

\section{B. Peraturan Perundang-undangan}

Undang-Undang Dasar Negara Republik Indonesia Tahun 1945 hasil Amandemen Undang-Undang Nomor 1 Tahun 2004 tentang Perbendaharaan Negara

Peraturan Presiden Republik Indonesia Nomor 54 Tahun 2010 tentang Pengadaan Barang/Jasa Pemerintah

Peraturan Presiden Republik Indonesia Nomor 70 Tahun 2012 tentang Pengadaan Barang/Jasa Pemerintah

Peraturan Menteri Agraria dan tata Ruang/Kepala Badan Pertanahan Nasional Republik Indonesia Nomor 38 tahun 2016 Tentang Organisasi dan Tata Kerja Kantor Wilayah Badan Pertanahan dan Kantor Pertanahan di Kabupaten/Kota

Peraturan Presiden Republik Indonesia Nomor 16 Tahun 2018 tentang Pengadaan Barang/Jasa Pemerintah

\section{Sumber Lain}

Jurnal Aspek Hukum Pengadaan Barang Dan Jasa Pemerintah Suatu Tinjauan Yuridis Peraturan Pengadaan Barang Dan Jasa Pemerintah, Media Hukum Vol. 24 No. 2

Jurnal Riset Akuntansi Going Concern. 2017. Analisis Sistem Pengadaan Barang Dan Jasa (Penunjung Langsung) Pada Di Dinas Pekerjaan Umum Dan Penataan Ruang Kota Manado. 


\section{PEDOMAN PENULISAN JURNAL PRANATA HUKUM}

1. Naskah bersifat orisinil, baik berupa hasil riset atau tinjauan atas suatu permasalahan hukum yang berkembang di masyarakat (artikel lepas), dimungkinkan juga tulisan lain yang dipandang memberikan kontribusi bagi pengembangan ilmu hukum.

2. Penulisan terdiri atas beberapa bab penulisan hasil penelitian terdiri dari 3BAB,yaitu ;

BAB I. PENDAHULUAN (Latar Belakang dan Rumusan Masalah) BAB II. PEMBAHASAN (Kerangka Teori dan Analisis), dan BAB III. PENUTUP (Kesimpulan dan Saran).

3. Tulisan menggunakan bahasa indonesia maupun bahasa inggris yang memenuhi kaidah bahasa yang baik dan benar,tulisan menggunakan bahasa indonesia disertai abstrak dalam bahasa inggris (200 kata) dan Kata kunci, ketentuan ini berlaku sebaliknya.

4. Setiap kutipan harus menyebutkan sumbernya, dan ditulis pada akhir kutipan dengan memberi tanda kurung (bodynote). Sumber kutipan harus memuat nama pengaran, tahun penerbitan dan halaman .Contoh : satu penulis (Bagir Manan, 1994: 20), Dua Penulis (Jimly Asshidiqqie dan M.Ali Syafa'at, 2005: 11), Tiga atau lebih penulis menggunakan ketentuan et.al (dkk). Untuk artikel dari internet dengan susunan: nama penulis, judul tulisan digaris bawah, alamat website, waktu download/unduh.

5. Naskah harus disertai dengan daftar pustaka atau referensi ,terutama yang digunakan sebagai bahan acuan langsung. Daftar pustaka dan referensi bersifat alfabetis dengan format; nama pengarang, judul buku, nama penerbit, kota terbit, dan tahun penerbitan. Contoh: Bagir Manan, Hubungan Antara Pemerintah Pusat dan Daerah Menurut UUD 1945, Pustaka Sinar Harapan, Jakarta, 1994.

6. Panjang tulisan antara 15-25 halaman, font times new roman dengan 1,15 spasi. Dalam hal hal tertentu berlaku pengecualian panjang tulisan.

7. Naskah disertai nama lengkap penulis, alamat e-mail dan lembaga tempat berafiliasi saat ini, dan hal lain yang dianggap penting. 


\section{Jurnal PRANATA HUKUM dimaksudkan sebagai}

media komunikasi, edukasi, dan informasi ilmiah bidang ilmu hukum khususnya, dan ilmu sosial pada umumnya. Sajian dan kemasan diupayakan komunikatif melalui bahasa ilmiah.

Redaksi mengundang semua elemen masyarakat baik civitas akademika, praktisi, lembaga masyarakat, maupun perorangan yang berminat terhadap bidang hukum untuk berpartisipasi mengembangkan gagasan, wawasan, dan pengetahuan melalui tulisan untuk dimuat dalam jurnal ini.

Melalui PRANATA HUKUM diharapkan terjadi proses pembangunan dan pengembangan bidang hukum sebagai bagian penting dari rangkaian panjang proses memajukan masyarakat bangsa.

Alamat Redaksi

PRANATA HUKUM

Kampus B Universitas Bandar Lampung Jl. ZA Pagar Alam No.89 Labuhan Ratu, Bandar

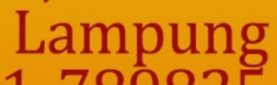

Telp: 0721-789825

Email: jurnal.mh@ubl.ac.id

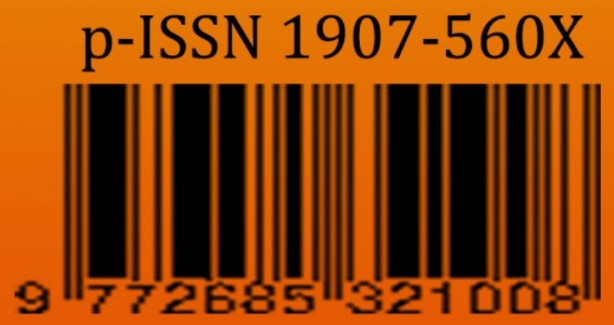

